\title{
Research on Energy Conservation and Emission Reduction Based on the Economic Transformation and Upgrading of Jiangsu Province in China
}

\author{
Guiliang Tian, Wei Gu, Changxin Xu, Rui Dai
}

Business School, HoHai University, Nanjing, China.

Email: tianguiliang@hhu.edu.cn, tianguiliang82@yahoo.com.cn

Received August 21 $1^{\text {st }}, 2012$; revised September 23 $3^{\text {rd }}, 2012$; accepted October $25^{\text {th }}, 2012$

\begin{abstract}
With China's rapid economic development, the economic transformation and emission reduction based on energy conservation are the two key problems of Chinese economic development. In this article, we made quantitative analysis to the energy conservation and emission reduction of Jiangsu industrial restructuring and industrial technology progress by using the model of input-output methods with the data of Jiangsu input-output table in 2007. The result showed that if energy consumption caused by per unit output in the industry higher than average level of all the industries, we can decrease its proportion of all the industries. However, if the industry is the pillar industry to the national economic development, we cannot largely decrease its proportion. During this background, improving the technical level of the Industry to reduce the energy consumption is a better choice. This article analyzed the contribution to energy conservation and emission reduction by industrial restructuring and industrial technology progress from the quantitative aspect.
\end{abstract}

Keywords: Economic Transformation and Upgrading; Energy Conservation and Emission Reduction; Input-Output Analysis

\section{Introduction}

Each county shows high attention to the resources and environment problems based on the situation of resource limitation and environmental serious damage. China has made a commitment of energy saving and emission reduction on the Copenhagen Climate Conference during 17-18 December 2009. As a major economic province in China, Jiangsu is also a province with relatively poor energy. With the rapid economic development in recent years, energy supply and demand keep increasing year after year. In future, economic development has great relationship to the energy in Jiangsu province. And it is necessary to analyze the ways of energy conservation and emission reduction based on the high attention of the "twelfth five-year plan".

\section{The Research Status of Energy Conservation and Emission Reduction \& Economic Transformation and Upgrading}

Many scholars have done a lot of research work on energy conservation and emission reduction. S. J. Liu found we should control the commission to the lowest level and the most economical level by analyzing the environmental Kuznets curve [1]. H. X. Shi considered that we should learn practice of the United States and Europe to promote Energy Conservation and Emission Reduction by market mechanism [2]. Y. F. Gu confirmed the effective of energy conservation and emission reduction, however, there existed the gap with per unit GDP energy consumption, so the potential energy conservation is great [3]. M. J. Ma demonstrated the urgency of developing the low-carbon economy by making a comparison between China and developed countries on the aspect of low-carbon economy [4]. J. Q. Bao considered that we can promote and reach the goal of economic transformation and upgrade by "forced mechanism" formed with energy intensity and total quantity of pollutants control index [5]. Y. J. Yuan built the economic transformation and upgrading model including energy conservation and emission reduction. By doing simulation, he found that economic transformation and upgrading can promote energy conservation and emission reduction, and can keep the increasing pace of economic development [6]. The above articles kept stay on the qualitative analysis of the efficiency on energy conservation and emission reuction by economic transformation and upgrading. This article proposed an innovative model which use the input-output method to quantify the effective of economic transformation and upgrading in order to get intuitive 
changes in value of the energy conservation and emission reduction. This method not only thinks out the correlation between the industries, but also get exactly amount of energy conservation and emission reduction by industrial restructuring and industrial technology improvement. The input-output method is one of the most appropriate methods to study the impact of the changes in the industrial structure currently. It makes a detailed description of the dependencies between the various industries by strict checkerboard table. The study estimates energy savings and emission reductions because of upgrading of the industrial structure of Jiangsu Province quantitatively. And the study estimates energy savings and emission reductions based on the impact of technological progress on the consumption coefficient under the technological advances. This analysis method fully takes into account the overall impact of the industrial economic system. Therefore, the results are more objective and realistic. Last, we gave some advice to Jiangsu Province on the model of industrial development based on the former conclusions.

\section{Quantitative Analysis of the Jiangsu Economic Transformation and Upgrading of the Energy Saving Effect}

\subsection{The Energy Saving Effect of Industrial Restructuring}

Firstly, this article builds a mathematical model of inputoutput tables with Jiangsu. Coal, oil and gas are considered as energy according to the input-output tables. We get the total consuming coefficient of oil and coal in each department from input-output tables in 2007, Jiangsuthe consumption of coal, oil and gas corresponding to the addition of one unit output in each department. Then, the sum of this result divided by 42 , we can get the consuming amount of coal, oil and gas by increasing one unit of GDP in the existing production structure, and using this result to divided by the consumption amount of coal, oil and gas which caused by one unit additional outputting of each sector, we can get the coefficient of each department. The larger coefficient it is, the consuming amount of coal, oil and natural gas caused by one unit of output in this department is more. When the coefficient of one department is less than 1, it shows the consumption of coal, oil and gas caused by each additional unit output of this sector is less than the amount caused by the increasing of one unit of GDP under the existing production structure. Instead, when the coefficient is higher than 1, it shows the consumption of coal, oil and gas caused by each additional unit output of this sector is more than the amount caused by the increasing of one unit GDP under the existing production structure. Calculation steps and the results are as follows.

In front of 42 departments in the input-output tables, the total consumption coefficient of the coal mining and washing were $x_{i} \quad(i=1,2,3, \cdots 42)$, which is arranged in order by industry input-output tables. Look-up table can be calculated: $X=\sum_{i=1}^{42} x_{i}=1.7912 . X$ represents the sum of the coal consumption amount by one unit end-use product and all indirect consumption of it in each production sector.

$$
X_{1}=\frac{x}{42}
$$

then $X_{1}$ is the coal consumption of one unit total production output, it means the amount of coal consumed by each additional unit of GDP in the current economic structure. The total consumption coefficient of the oil and gas in front of 42 departments in the input-output tables were $y_{i}(i=1,2,3, \cdots 42)$. Look-up table can be calculated:

$$
Y=\sum_{i=1}^{42} y_{i}=4.0585
$$

$Y$ represents the sum of the oil and gas consumption amount by one unit end-use product and all indirect consumption of it in each production sector in the current economic structure. Given

$$
Y_{1}=\frac{Y}{42}
$$

then $Y_{1}$ means the oil and gas consumed by one unit total production output, it means the amount of oil and gas consumed by each additional unit of GDP in the current economic structure. Then $Z=X_{1}+Y_{1}=0.1392776$, it represents that the consumption amount of coal, oil and gas is 0.1392776 unit when increase one unit of GDP in the current economic structure. In front of 42 departments in the input-output tables, the total consumption amount of the coal, oil and gas were $Z_{i}=X_{i}+Y_{i}(i=1,2,3, \cdots 42)$. So it can get 42 departments coefficient:

$$
\alpha_{i}=\frac{Z_{i}}{Z}(i=1,2,3, \cdots 42), \beta_{i}=1-\alpha_{i}(i=1,2,3, \cdots 42)
$$

so $\beta_{\mathrm{i}}$ is refers to the gap between the total consumption amount of coal, oil and gas which results from one unit output in this department and it caused by one unit GDP addition under the existing production structure.

From the flow statement of input-output tables, we can know output value of 42 industries is respectively $\mathrm{G}_{i}(i=1,2,3, \cdots 42)$, we can get the energy consumption of one GDP unit which is 0.853 tons of standard coal/ million. For example, according to the analysis of the above, if the output of 42 departments respectively increased by $20 \%$, we can calculate the savings in energy 
consumption resulted from developing some industry instead of the same additional amount of GDP in the existing production structure, calculation process is following:

$$
\Delta_{i}=20 \% \cdot G_{i} \times \beta_{i} \times 0.853,(i=1,2,3 \cdots 42)
$$

Then we discuss waste gas reducing effect of 42 industries. In 2007, the total output value of Jiangsu area is 2601.848 billion Yuan, the exhaust gas is 2354.7 hundred million standard cubic meters, so that the exhaust gas of one unit GDP is 0.90501 hundred million standard cubic meters/hundred million Yuan. Change the energy consumption of one unit GDP in the above formula (1) to the exhaust gas of one unit GDP, we can calculate the decrement of the exhaust gas which is represented by $D_{i}$, then obtains the formula:

$$
D_{i}=20 \% \cdot G_{i} \times \beta_{i} \times 0.905(i=1,2,3, \cdots 42)
$$

The primary data, the middle data as well as the final data involving in above computational process are shown in Table 1. From line $\alpha_{i}$ in Table 1 there are coefficient of 42 departments, the bigger coefficient means that the department consumes more amount of coal, petroleum and natural gas when produces a unit output. The coefficient which is smaller than 1 means that increasing one unit output of this department consumes less amount of coal, petroleum and natural gas than one unit addition of GDP under the present production structure. The coefficient bigger than 1 namely indicates that increasing one unit output of this department consumes more coal, Petroleum and natural gas than increasing one unit GDP under the present production structure. In the table there are 30 departments' coefficient smaller than 1. Among these 30 departments there are 12 departments the $\beta_{i}$ value of which are bigger than 0.5 . They are the agricultural forestry, the food industry, the waste product industry, the information industry, the wholesale business, residential and food industry, the financial industry, the room industry, the research experiment, the education, the Healthcare, the public service administration. It means the energy consumption caused by increasing a unit output of these industries can save more than $50 \%$ than increasing a unit GDP under the present production structure. The coefficient of the financial industry $(0.8254)$ is the largest, and its energy saving amount is 230.9039 ten thousand tons standard coal, its amount of exhaust emission is 244.980 hundred million standard cubic meters. But the amount of the energy saving and exhaust emission of the financial industry are not the largest. The largest amount of energy saving and the largest amount of exhaust emission is the information industry (511.5336 ten thousand tons standard coal and 542.7173 hundred million standard cubic meters). Because the total output of the information industry is the largest. The other industries are also similar to the financial industry. We can conclude that the amount of energy saving and exhaust emission depend on the coefficient and the total output of the industry. The value of the waste product industry is the biggest, but this industry is quite special, so it can't be developed vigorously. It can make a very great degree reduction of energy consumption amount and the emission quantity of exhaust gas to increase the total output of other 11 industries. The concrete data can refer to next table. Therefore we should develop these 11 industries vigorously from the innovation angle. In Table 1 there are the concrete reduction data of the energy consumption and the waste gas withdrawal when the above mentioned 11 departments increase $20 \%$ total outputs.

\subsection{Energy Saving Effect of Industrial Technology Improvement}

As we can see from above that the advanced manufacturing industry plays a promoting and supporting role in the economy and its energy consumption and emission quantity of exhaust gas are both lower than the average level of other industries, these sectors should be vigorously developed. We can also see from Table 1 that the coefficients of coal industry, petroleum exploit industry, metal mine, nonmetal and petroleum processing industry, chemical industry, non-metal manufacturing industry, metallurgical industry, metal manufacturing industry, electricity manufacturing industry, gas industry and transportation industry are greater than 1 , especially the oil processing industry (5.8422), the gas industry (4.9488) and the electricity manufacturing industry (2.3556). Although it would consume much more energy to increase the output of these departments than to increase the same amplitude of GDP, we still have to develop these traditional industries as the same to develop advanced Industries and other emerging industries because they are heavy industries and play a significant supporting role in the national economy. So it is necessary to make technical improvement of these industries in order to reduce the complete consumption coefficient of coal mining and washing industry and petroleum and gas extracting industry.

According to the Twelfth Five-Year Plan of Jiangsu Province, the energy consumption of per unit GDP needs to be reduced by 16 percent, so we should reduce the complete consumption coefficient of the twelve Industries to coal mining and washing industry, oil and gas mining industry. Set $S_{i}(i=1,2, \cdots 12)$ refers to the energy (coal, gas and oil) consumption caused by one additional unit of GDP of these twelve industries. If the complete consumption coefficient of the twelve industries to coal mining and washing industry, oil and gas mining 
Table 1. Energy conservation and pollution reduction effect of industrial structure.

\begin{tabular}{|c|c|c|c|c|c|c|c|c|}
\hline Industrial sector & Coal industry & $\begin{array}{l}\text { Petroleum } \\
\text { extraction }\end{array}$ & $Z_{i}$ & $\alpha_{i}$ & $\beta_{i}$ & Total output & $\begin{array}{c}\text { Amount of } \\
\text { energy saving }\end{array}$ & $\begin{array}{c}\text { Amount of } \\
\text { waste reduction }\end{array}$ \\
\hline Agriculture and forestry & 0.0129 & 0.0353 & 0.0482 & 0.3458 & 0.6542 & 3064.7200 & 342.0167 & 362.8664 \\
\hline Petroleum extraction & 0.0429 & 0.1031 & 0.1460 & 1.0479 & -0.0479 & 71.5112 & -0.5847 & -0.6203 \\
\hline Metal mine & 0.0626 & 0.1217 & 0.1843 & 1.3234 & -0.3234 & 58.8865 & -3.2493 & -3.4474 \\
\hline Food industry & 0.0183 & 0.0401 & 0.0584 & 0.4193 & 0.5807 & 230.4955 & 22.8343 & 24.2263 \\
\hline Cottonocracy & 0.0332 & 0.0639 & 0.0972 & 0.6976 & 0.3024 & 5022.9756 & 259.1453 & 274.9431 \\
\hline Garment manufacturing industry & 0.0294 & 0.0590 & 0.0883 & 0.6342 & 0.3658 & 2397.0268 & 149.5915 & 158.7108 \\
\hline Furniture manufacturing industry & 0.0413 & 0.0699 & 0.1112 & 0.7983 & 0.2017 & 807.1456 & 27.7671 & 29.4598 \\
\hline Literary and sports manufacturing industry & 0.0361 & 0.0664 & 0.1025 & 0.7363 & 0.2637 & 1406.0636 & 63.2551 & 67.1113 \\
\hline Chemical industry & 0.0625 & 0.1824 & 0.2449 & 1.7586 & -0.7586 & 9599.2642 & -1242.2824 & -1318.0135 \\
\hline Nonmetal manufacturing industry & 0.1075 & 0.1038 & 0.2113 & 1.5169 & -0.5169 & 1541.5596 & -135.9391 & -144.2261 \\
\hline Smelting industry & 0.0738 & 0.1137 & 0.1876 & 1.3468 & -0.3468 & 7677.8996 & -454.2475 & -481.9390 \\
\hline Metal manufacturing & 0.0582 & 0.0919 & 0.1501 & 1.0776 & -0.0776 & 2346.2558 & -31.0423 & -32.9347 \\
\hline General manufacturing industry & 0.0471 & 0.0795 & 0.1266 & 0.9088 & 0.0912 & 5450.3033 & 84.7817 & 89.9501 \\
\hline Traffic manufacturing industry & 0.0357 & 0.0670 & 0.1027 & 0.7371 & 0.2629 & 2702.7057 & 121.1977 & 128.5861 \\
\hline Electric industry & 0.0448 & 0.0805 & 0.1252 & 0.8992 & 0.1008 & 4505.2750 & 77.4729 & 82.1958 \\
\hline Correspondence manufacturing industry & 0.0301 & 0.0598 & 0.0899 & 0.6454 & 0.3546 & 8456.8102 & 511.5336 & 542.7173 \\
\hline Instrument manufacturing industry & 0.0356 & 0.0684 & 0.1040 & 0.7469 & 0.2531 & 881.0114 & 38.0481 & 40.3676 \\
\hline Handicraft manufacturing industry & 0.0409 & 0.0709 & 0.1118 & 0.8026 & 0.1974 & 286.2860 & 9.6393 & 10.2269 \\
\hline Electric power manufacturing industry & 0.2209 & 0.1072 & 0.3281 & 2.3556 & -1.3556 & 2192.9466 & -507.1603 & -538.0775 \\
\hline Fuel gas industry & 0.1027 & 0.5866 & 0.6893 & 4.9488 & -3.9488 & 102.0742 & -68.7634 & -72.9553 \\
\hline Water industry & 0.0519 & 0.0563 & 0.1082 & 0.7770 & 0.2230 & 61.9119 & 2.3559 & 2.4995 \\
\hline Architecture industry & 0.0488 & 0.0878 & 0.1366 & 0.9808 & 0.0192 & 4849.6855 & 15.9080 & 16.8778 \\
\hline Transportation industry & 0.0251 & 0.1642 & 0.1893 & 1.3594 & -0.3594 & 2107.1235 & -129.2024 & -137.0788 \\
\hline Postal service industry & 0.0190 & 0.0629 & 0.0819 & 0.5879 & 0.4121 & 60.1461 & 4.2288 & 4.4866 \\
\hline Information industries & 0.0163 & 0.0304 & 0.0467 & 0.3353 & 0.6647 & 844.2400 & 95.7409 & 101.5774 \\
\hline Wholesale establishment & 0.0075 & 0.0203 & 0.0279 & 0.2003 & 0.7997 & 2927.7064 & 399.4372 & 423.7874 \\
\hline Food and hotel industry & 0.0180 & 0.0375 & 0.0555 & 0.3988 & 0.6012 & 1051.4668 & 107.8485 & 114.4231 \\
\hline Finance & 0.0070 & 0.0173 & 0.0243 & 0.1746 & 0.8254 & 1639.7900 & 230.9039 & 244.9801 \\
\hline Room industry & 0.0068 & 0.0195 & 0.0263 & 0.1888 & 0.8112 & 1422.5700 & 196.8730 & 208.8747 \\
\hline Rents industry & 0.0246 & 0.0681 & 0.0927 & 0.6654 & 0.3346 & 1130.0262 & 64.5076 & 68.4401 \\
\hline Research experiment & 0.0210 & 0.0450 & 0.0660 & 0.4740 & 0.5260 & 164.5943 & 14.7694 & 15.6698 \\
\hline Technology industry & 0.0226 & 0.0624 & 0.0851 & 0.6108 & 0.3892 & 395.7983 & 26.2815 & 27.8837 \\
\hline Water conservation industry & 0.0232 & 0.0538 & 0.0769 & 0.5525 & 0.4475 & 226.1000 & 17.2623 & 18.3147 \\
\hline Service industry & 0.0226 & 0.0532 & 0.0758 & 0.5440 & 0.4560 & 835.7312 & 65.0158 & 68.9792 \\
\hline Education & 0.0147 & 0.0268 & 0.0415 & 0.2980 & 0.7020 & 952.0857 & 114.0284 & 120.9797 \\
\hline Health & 0.0330 & 0.0735 & 0.1065 & 0.7645 & 0.2355 & 661.3698 & 26.5734 & 28.1934 \\
\hline Culture & 0.0155 & 0.0347 & 0.0502 & 0.3603 & 0.6397 & 328.7337 & 35.8767 & 38.0638 \\
\hline Public service administration & 0.0147 & 0.0354 & 0.0502 & 0.3604 & 0.6396 & 1159.9800 & 126.5777 & 134.2941 \\
\hline
\end{tabular}


industry fell by 16 percent, the $Z$ value in the previous section will change according to the above calculation process.

The result of the calculation is:

$$
X^{\prime}=1.6286, Y^{\prime}=3.6572, Z^{\prime}=\frac{X^{\prime}+Y^{\prime}}{42}=0.125852
$$

Respectively get the coefficients of the twelve departments:

$$
\beta_{i}=\frac{s_{i}}{z^{\prime}}(i=1,2, \cdots 12)
$$

Set $c_{i}(i=1,2, \cdots 12)$ refers to the total output of the twelve departments, under the premise that the total output of the twelve departments do not changed, we must reduce the complete consumption coefficient of the twelve departments to coal, oil and gas to reduce the emissions.

It means reduce $S_{i}$ by $16 \%$ :

$S_{i}^{\prime}=(1-16 \%) S_{i}, i=1,2, \cdots 12, \beta_{i}^{\prime}=\frac{s_{i}^{\prime}}{z}(i=1,2, \cdots 12)$

From above we got:

$\Delta_{i}^{\prime}=C_{i} \cdot \beta_{i} \cdot$ energy consumption per unit of $G D P$

$-C_{i} \cdot \beta_{i}^{\prime} \cdot$ energy consumption per unit of GDP

$=C_{i} \cdot$ energy consumption per unit of $\operatorname{GDP}\left(\beta_{i}-\beta_{i}^{\prime}\right)$

= energy consumption per unit of GDP. $\frac{c_{i}}{z}\left(s_{i}-s_{i}^{\prime}\right)$

Then

$$
\Delta_{i}^{\prime}=0.853 \cdot \frac{c_{i}}{z^{\prime}} \cdot 16 \% s_{i}, \quad i=1,2, \cdots 12
$$

Then we replaced energy consumption of per unit GDP by exhaust emission of per unit GDP to calculate the reduction of the exhaust emission caused by per unit of GDP:

$$
P_{i}^{\prime}=0.905 \cdot \frac{c_{i}}{z^{\prime}} \cdot 16 \% s_{i}, \quad i=1,2, \cdots 12
$$

All the related raw data, intermediate data and final data are shown in the following Table 2.

It can be seen from Table 2 that under the premise that the total output of the twelve departments remains unchanged, the energy consumption would relatively decrease by 16 percent as we reduce the complete consumption coefficient of the twelve departments to coal, oil and gas by 16 percent. The total demand coefficient of oil processing to Coal industry, Oil and gas mining $(0.81)$ is the largest, and its energy saving amount is 882.14 ten thousand tons standard coal, its amount of exhaust emission is 935.92 hundred million standard cubic meters, and the amount of the energy saving and exhaust emission of the oil processing are not the largest, but only the third largest because its output is less than 1000 hundred million Yuan. The largest amount of energy saving and the largest amount of exhaust emission is the Chemical industry (2549.71 ten thousand tons standard coal and 2705.15 hundred million standard cubic meters). Because the total output of the Chemical

\begin{tabular}{|c|c|c|c|c|c|c|}
\hline Abbreviation & Coal industry & Oil and gas mining & $S_{i}$ & Total output & Energy saving & Emission reduction \\
\hline Coal industry & 0.14 & 0.06 & 0.20 & 178.42 & 38.6 & 40.95 \\
\hline Metal mining & 0.06 & 0.12 & 0.18 & 58.89 & 11.77 & 12.49 \\
\hline Non-metal mining & 0.05 & 0.13 & 0.18 & 110.74 & 21.64 & 22.96 \\
\hline Oil processing & 0.07 & 0.75 & 0.81 & 999.71 & 882.14 & 935.92 \\
\hline Chemical industry & 0.06 & 0.18 & 0.24 & 9599.26 & 2549.71 & 2705.15 \\
\hline Non-metal manufacturing & 0.11 & 0.10 & 0.21 & 1541.56 & 353.19 & 374.72 \\
\hline Metallurgical industry & 0.07 & 0.11 & 0.19 & 7677.90 & 1561.83 & 1657.04 \\
\hline Metal manufacturing & 0.06 & 0.09 & 0.15 & 2346.26 & 381.86 & 405.14 \\
\hline Electricity industry & 0.22 & 0.11 & 0.33 & 2192.95 & 780.23 & 827.8 \\
\hline Gas industry & 0.10 & 0.59 & 0.69 & 102.07 & 76.3 & 80.95 \\
\hline Transportation industry & 0.03 & 0.16 & 0.19 & 2107.12 & 432.65 & 459.02 \\
\hline
\end{tabular}
industry (9599.26 hundred million Yuan) is the largest. The second of energy saving and emission reduction is

Table 2. Energy saving effect of industrial technology improvement. 
metallurgical industry, 1561.83 ten thousand tons standard coal and 1657.04 hundred million standard cubic meters. Although the total demand coefficient of metallurgical industry to Coal industry, Oil and gas mining (0.21) is not very large, the total output of metallurgical industry is the second. So we can conclude that the amount of energy saving and exhaust emission depend on the coefficient and the total output of the industry. As we know, the total output of oil processing industry, chemical industry, non-metal manufacturing industry, metallurgical industry, metal manufacturing industry, electricity manufacturing industry and transportation industry was as much as over one hundred billion Yuan, so the reduction of energy consumption and exhaust emissions would be relatively large by reducing the complete consumption coefficient. Besides, as the complete consumption coefficient of the oil processing industry, chemical industry, nonmetal manufacturing industry, electricity industry, gas industry are relatively large, it would also bring significant energy saving and exhaust emission reduction by reducing the complete consumption coefficient of these departments. As a conclusion, we should upgrade the technology, improve the management and eliminate the backward equipment and production capacity of these twelve departments we mentioned above.

\section{Conclusions and Recommendations}

The major categories of industrial transformation can be divided into two types: industrial structure adjustment and industrial technology development. In order to realize the target that driven by high consumption of material resources changes to driven by innovation, extensive growth changes to intensive development, we should vigorously develop the service industry and high-tech industry and focus on the industries with low energy consumption, high development potential and large influence on the national economy to improve the proportion of industrial output value in GDP. However, we cannot com- pletely abandon those traditional industries with high energy consumption and high pollution for they play a significant role in the national economy. We should transform these industries by technology upgrading, merger and reorganization, elimination of backward production capacity to reduce the energy consumption and pollution of these industries.

\section{Acknowledgements}

The authors would like to acknowledge to staff form Research Institute of Jiangsu Province Government for comments and suggestions. This study was funded by the National Natural Science Foundation of China (Grant No. 41001377) and Social Sciences Fund of Jiangsu Province (Grant No. 10GLC013).

\section{REFERENCES}

[1] S. J. Liu, "Environmental Kuznets Curve and Energy Conservation and Emission Reduction," Environmental Protection, Vol. 35, No. 24, 2007, pp. 31-32.

[2] H. X. Shi, "The Promotion of Energy Conservation and Emission Reduction by Market-Oriented Policies," Theory Front, Vol. 509, No. 4, 2007, pp. 37-38.

[3] Y. F. Gu, "Jiangsu Energy Conservation Status and Countermeasure," Energy Research \& Utilization, Vol. 19, No. 5, 2007, pp. 1-4.

[4] M. J. Ma and X. L. Zhao, "China's New Energy Strategy Under Low-Carbon Economy," Reformation \& Strategy, Vol. 26, No. 8, 2010, pp. 11-12.

[5] J. Q. Bao, "Energy Conservation and Emission Reduction Needs New Thinking, New Path and New Mechanism," Zhejiang Economy, Vol. 26, No. 21, 2009, pp. 10-11.

[6] Y. J. Yuan and K. Dong, "The Research of China Industrial Structure Optimization Problem Based on Constraint of Energy Conservation and Emission Reduction," Industrial Technology \& Economy, Vol. 27, No. 8, 2008, pp. 53-55. 